\title{
EDUCAÇÃO E ÉTICA SOB O ENFOQUE DA ABORDAGEM DAS CAPACIDADES ${ }^{1}$
}

\author{
EDUCATION AND ETHICS FOCUSING ON THE CAPABILITIES APPROACH \\ EDUCACIÓN Y ÉTICA BAJO EL ENFOQUE DEL ABORDAJE DE LAS CAPACIDADES
}

\author{
Mauricio João Farinon \\ Professor Doutor da Universidade do Oeste de Santa Catarina (UNOESC). \\ Joaçaba - SC, Brasil. \\ mauricio.farinon@unoesc.edu.br
}

RESUMO: Inserido na problemática referente à abordagem das "capacidades" de Amartya Sen em sua articulação com a educação, este texto visa a refletir sobre o conceito de capacidade em sua relação com a liberdade e a responsabilidade, apontando a relevância da educação como processos comprometidos com as condições pelas quais os indivíduos se tornam aptos a valorar suas decisões e ações, o que repercute na realização de atos justos. Com foco em pesquisa de cunho teórico, são apontados o convite à ação da responsabilidade e o convite à razão como critérios para romper com o exclusivo autointeresse e a consequente valoração das realizações humanas em seus sentidos e desafios éticos.

PALAVRAS-CHAVE: Educação. Formação. Capacidade. Liberdade. Amartya Sen.

ABSTRACT: As part of Amartya Sen's approach to "capability" in its articulation with education, this text aims to reflect on the concept of capability in its relation to freedom and responsibility, pointing to the relevance of education as processes committed to the conditions by which the individuals become apt to value their decisions and actions, which has repercussions in the performance of fair acts. Focusing on theoretical research, are pointed out the call to action of responsibility and the invitation to reason as criteria to break with the exclusive self-interest and the consequent valuation of human achievements in their ethical senses and challenges.

KEYWORDS: Education. Formation. Capability. Freedom. Amartya Sen.

RESUMEN: Insertado en la problemática relativa al enfoque de las "capacidades" de Amartya Sen en su articulación con la educación, este texto pretende reflexionar sobre el concepto de capacidad en su relación con la libertad y a la responsabilidad, señalando la importancia de la educación como procesos comprometidos con las condiciones por las cuales los individuos se vuelven aptos de valorar sus decisiones y acciones, lo que repercute en la realización de actos justos. Con foco en investigación de cuño teórico, son señaladas la invitación a la acción de responsabilidad y la invitación a la razón como criterios para romper el autointerés exclusivo y la valoración resultante de las realizaciones humanas en sus sentidos y desafíos éticos.

PALABRAS CLAVE: Educación. Formación. Capacidad. Libertad. Amartya Sen.

\footnotetext{
${ }^{1}$ Este artigo é resultado da pesquisa intitulada "A abordagem das capacidades em sua articulação ético-formativa", realizada com apoio financeiro do CNPq sob a Chamada MCTI/CNPQ/MEC/CAPES n. 22/2014, Ciências Humanas e Sociais.
}

$\overline{\text { Artigo recebido em maio de } 2017}$

Aprovado em julho de 2017 


\section{1| INTRODUÇÃO}

Em 2008, em artigo publicado no Journal of Human Development, e intitulado "The idea of justice", Amartya Sen expôs alguns indicativos presentes em sua concepção de justiça, dentre os quais, dois apresentam de modo direto um convite à ação: a centralidade na vida e liberdade, a vinculação da responsabilidade ao poder efetivo. Tanto em relação à centralidade posta, quanto em relação à vinculação estabelecida, a justiça não se caracteriza apenas pela condição de os indivíduos adquirirem ou possuírem determinados bens, ou realizarem determinadas ações, mas:

a) caracteriza-se pela condição de converter os bens em qualidade de vida, em bem viver;

b) pela condição de ser agente livre para realizações, o que implica o critério de valorações feitas pelo indivíduo que age;

c) no desenvolvimento da consciência de que o poder de ação é, em última instância, a ação da responsabilidade.

Com este texto defendo que a concepção seniana de capacidade é resultante da realização desses indicativos sobre justiça. De modo geral, almejo refletir sobre o conceito de capacidade em sua relação com a liberdade e a responsabilidade, apontando a relevância própria da educação enquanto processos comprometidos com as condições pelas quais os indivíduos se tornam aptos a valorar suas decisões e ações, o que repercute na realização de atos justos. Os escritos de Sen, economista e filósofo, Nobel de Economia em 1998, não possuem relação direta com a área da Educação, o que gera dificuldade e intensos desafios nas pesquisas referentes a tal autor e a tal relação temática.

É importante destacar, em termos introdutórios, alguns caminhos de reflexão que podem orientar a leitura da obra seniana:

a) preocupação com as realizações possíveis ao indivíduo, uma vez sendo parte de uma instituição ou habitando um contexto marcado por determinadas características e por um conjunto de normas e valores. $O$ foco posto nas realizações remete à preocupação com o comportamento real das pessoas, com aquilo que surge de modo efetivo e vinculado à vida que as pessoas são, de fato, capazes de viver, e não na suposição de um seguimento daquilo que se estabelece como sendo o comportamento ideal, próprio da juridificação ou institucionalismo ;

b) com as realizações, surge a preocupação com a liberdade, a qual ocorre quando somos capazes de agir de modo valorado;

c) com a valoração somos postos diante do desafio de não ficarmos reduzidos à nossa posição original, o que exige abertura à perspectivas provenientes de outros lugares, outras culturas, outras pessoas; ${ }^{2}$

d) essa abertura repercutirá na ampliação do leque informacional, na potencialização do debate interativo e, se acompanhado pela qualificação teórica, podem ocorrer análises, escolhas e realizações arrazoadas.

O condicional utilizado ao falar sobre a teoria se deve à qualificação interna que ela gera e a partir da qual a argumentação adquire um caráter racional, sendo que sua presença ou ausência ressoa na possível superação da arbitrariedade ou subjetivismo existente nas análises, escolhas e realizações.

Dentro desse contexto teórico é fundamental refletirmos sobre a educação e seus processos formativos, conscientes dos desafios que envolvem a formação sob o foco das capacidades e liberdades, para além de processos preocupados com a mera instrumentalização e juridificação das ações.

\footnotetext{
${ }^{2}$ Sobre o tema da juridificação ou institucionalismo, ver: Flickinger (2015). A tensão entre realizações e juridificação/ institucionalismo é tema que será retomado no decorrer deste texto.
} 


\section{2 | SOBRE A RELAÇÃO ENTRE JUSTIÇA E LIBERDADE}

"Procedamos com justiça". Esse imperativo de Shakespeare, em sua tragédia O Rei Lear, remete para a problemática da fragilidade nos critérios a partir dos quais atribuímos valor, tomamos decisões e agimos. A ausência do procedimento justo pode ser colocada como sendo a causa do problema existencial e de poder que assolou Lear, e um aspecto que chama a atenção nessa obra é o fato de a justiça não estar sendo debatida em termos conceituais, mas enquanto característica de sabedoria que deve integrar as realizações e a partir da qual se evitariam ou minimizariam os efeitos da roda da fortuna. Ao mesmo tempo, estamos diante da preocupação imediata com o mal que se pode evitar mediante o modo como procedemos, pois, da justiça, "basta um som de tua bela boca, que não lhes ocorre nada de mal" (SHAKESPEARE, 2009, p. 738).

$\mathrm{O}$ que trago como destaque é a centralidade posta no procedimento, o que não descarta a necessidade de se construírem concepções e de se buscar o recurso da argumentação fundamentada, o recurso à teoria. Mas, quando falo do mal que queremos evitar, ou da injustiça que buscamos suprimir, estamos diante da necessidade de ocorrer a oportunidade e a liberdade de escolhas, as quais necessitam do acompanhamento da oportunidade e liberdade de ação. Contudo, a oportunidade e a liberdade não podem ser consideradas somente em seu aperfeiçoamento, sendo necessário, primeiramente, promover ou originar essa qualidade própria nos indivíduos.

A discussão em torno das realizações surge em contraposição ao tema do contratualismo, o qual conta como principais representantes autores como Thomas Hobbes, John Locke, JeanJacques Rousseau, Immanuel Kant e John Rawls. Em tais filósofos ocorre a tentativa de identificar os melhores arranjos institucionais de uma sociedade, propostas que surgem a partir do contrato social, ou a partir de imperativos morais e políticos. Para Sen (2011, p. 37), existe um "contraste radical entre uma concepção de justiça focada em arranjos e uma concepção focada em reali-zações: esta necessita, por exemplo, concentrar-se no comportamento real das pessoas, em vez de supor que todas sigam o comportamento ideal" pautado pelo contratualismo e institucionalismo.

Em referência ao tema das realizações, Amartya Sen assume papel fundamental, principalmente pelas suas discussões direcionadas ao tema da justiça. Não se pode negar o papel instrumental que as instituições ocupam nesse espaço, pois elas tendem a influenciar modos de conduta, seja de modo prescritivo ou formativo, gerando "oportunidades para o debate público (incluindo considerações da liberdade de expressão e do direito à informação, bem como a existência de locais para o debate informado)" (SEN, 2011, p. 15).

Mas, pressupor que os indivíduos agirão de modo justo considerando somente os arranjos institucionais, é algo que não nos leva muito longe, pois quando nos referimos aos comportamentos reais, pode não ocorrer coerência entre a norma instituída e a realização ocorrida ou, ainda, o seguimento da norma sem um processo de escolha e decisão. Com isso, a chamada transgressão de comportamento pode não ser necessariamente resultante de efeitos institucionais, mas de disposições comportamentais que direcionam a ação para características diferentes daquelas previstas pela regra instituída. Em termos de justiça - e para se manter fiel ao conteúdo da obra A ideia de justiça -, com o institucionalismo propõe - se que ela

seja conceitualizada quanto a certos arranjos organizacionais - algumas instituições, algumas regulamentações, algumas regras comportamentais -, cuja presença ativa indicaria que a justiça está sendo feita. Nesse contexto, a pergunta a ser feita é: a análise da justiça necessita limitar-se ao acerto das instituições básicas e das regras gerais? Não deveríamos também examinar o que surge na sociedade, incluindo os tipos de vida que as pessoas podem levar de fato, dadas as instituições e as regras, e também outras influências, incluindo os comportamentos reais, que afetam inescapavelmente as vidas humanas? (SEN, 2011, p. 40). 
Como exemplo de arranjos organizacionais cito as leis presentes nos mais diversos códigos, a própria noção de "contrato" que congrega os envolvidos em uma sociedade ou instituições sociais, as políticas públicas que regulamentam direitos básicos como acesso a serviços de saúde, de controle epidemiológico, de educação, de condições dignas de trabalho. Esses arranjos constituem um âmbito normativo necessário para gerar certa unidade ou equilíbrio no interior de determinada sociedade. Contudo, cabe a pergunta pela sua suficiência quando nos deparamos com a vida que as pessoas de fato são capazes de levar, ou seja, como as suas efetivas realizações.

Em Desenvolvimento como liberdade, Sen distingue entre entitlement e right, sendo que ambos se relacionam com direitos, mas aquele faz referência ao conjunto de planos, programas, disposições ou arranjos sociais que visam garantir direitos, como por exemplo, as políticas educacionais, políticas de saúde, de moradia etc., enquanto direito apenas presumido. Right, por sua vez, faz referência ao direito efetivo, àquilo que nos é garantido e disponibilizado efetivamente, ao mesmo tempo em que indica a possibilidade de os indivíduos buscarem e serem atendidos naquilo que é garantido via disposição ou arranjos de uma sociedade. Para melhor esclarecer essa distinção, proponho uma articulação com o tema referente ao institucionalismo e as realizações. A distinção entre institucionalismo e realizações surge de modo preocupante, pois os programas governamentais apontam para certos direitos que podem não encontrar correspondência satisfatória em sentido empírico. Como mera ilustração, sem pretensão de expor crítica, a busca pelo direito de um sistema educacional inclusivo, a qual é apontada como meta brasileira do Plano Nacional De Educação (PNE) em vigor, pode esbarrar não em uma fragilidade em termos de entitlement, mas em termos de comportamento real dos responsáveis pelas ações pedagógicas, o que compromete a disponibilização ou efetivação de tal direito (right).

A solução jurídica posta a esse problema é a mais óbvia e rápida, porém ilusória, pois remete novamente e tão somente ao institucionalismo. Esta é a juridificação dos conflitos e do próprio espaço pedagógico, denunciada por Flickinger (2015), a qual põe no cumprimento das determinações legais o critério de valoração, retirando qualquer impulso de vida que permita a formação. Nesse sentido é que a preocupação referente ao acerto das instituições deve ser acompanhada pela mesma preocupação com o acerto nas realizações, o qual não é compreendido enquanto juridificação, adequação ou dedução entre a forma da lei e a ação, mas no sentido de tornar o ser humano capaz de escolher, decidir e agir orientado por um forte senso ético e poder de raciocínio.

Nesse debate ressurge o problema entre a realização e a liberdade. A realização pode ser determinada a partir da prerrogativa institucional, não significando a passagem por valorações, escolhas e decisões, sendo tão somente a representação empírica do formalismo de um arranjo institucional. Sen atribui maior importância na liberdade de realização do que somente na reali-zação, pois considerar "as realizações da agência ou a liberdade da agência desloca o foco de uma pessoa como mero veículo de bem-estar e deixa de ignorar a importância de seus próprios juízos e prioridades, com os quais a agência se relaciona" (SEN, 2011, p. 322).

Um destaque deve ser enfatizado em relação à importância dos próprios juízos e prioridades. Os juízos próprios são compreendidos como consequência do poder de raciocínio, o qual significa "capacidade de pensar de forma mais clara sobre nossas metas, objetivos e valores" (SEN, 2011, p. 62), apontando para prioridades que estão além da busca autocentrada, inserindo a necessidade ética provinda do dever de

pensar mais claramente sobre nossas preocupações e responsabilidades sociais. Temse argumentado que algumas crianças levam a cabo atos de brutalidade contra outras crianças, ou animais, precisamente devido a sua incapacidade de compreender de forma adequada a natureza e a intensidade das dores dos outros, e que essa compreensão com frequência acompanha o desenvolvimento intelectual da maturidade. (SEN, 2011, p. 63). 
Com o cuidado para não reduzir a dor do outro à minha representação ou ato intelectivo, é importante destacar a defesa seniana da argumentação como método para evitar reducionismos e arbitrariedades. Ou seja, se o poder de raciocínio pode nos levar a agir bem, isso ocorre por elevarmos ao "exame crítico as opiniões prevalecentes e as razões alegadas" (SEN, 2011, p. 66). Em outra passagem, o autor relaciona como necessária a argumentação a partir de fundamentos que permitam ver os outros e nós mesmos livres de preconceitos ou sobreposições:

A argumentação é uma fonte robusta de esperança e confiança em um mundo obscurecido por atos sombrios - passados e presentes. Não é difícil ver por quê. Mesmo quando achamos algo imediatamente perturbador, podemos questionar nossa reação e perguntar se é uma reação adequada e se devemos de fato ser guiados por ela. A argumentação pode estar envolvida com a maneira correta de ver e tratar as outras pessoas, outras culturas, outras reivindicações, e com a análise de diferentes fundamentos para o respeito e a tolerância. Nós também podemos raciocinar sobre nossos próprios erros e tentar aprender a não repeti-los. (SEN, 2011, p. 76-77).

A argumentação tende a desautorizar ou evitar os pré-julgamentos ou pré-conceitos e, também, a colocação do autointeresse como base suprema para as realizações, o que levaria à uma centralidade na busca pelo bem-estar pessoal, implodindo todo discernimento justo e qualquer possível compromisso interpessoal. A confiança posta na possibilidade de ocorrer a argumentação, orientada pelo poder de raciocínio, garante soluções aos conflitos se tal ocorrência for permeada pela capacidade de perceber o outro em sua possível legitimidade, e não nos reduzirmos à afirmação absoluta de nós mesmos. Tem-se, aqui, a ideia de que a argumentação como poder do raciocínio não possui prioridade absoluta nas relações interpessoais e nas soluções de conflitos. A capacidade perceptiva pode ser posto em termos de experiência estética ${ }^{3}$, a qual "põe em movimento esse outro lado da razão - o sentimento, a sensibilidade, as emoções e o corpóreo", desfazendo a ilusão "de que o ser verdadeiro do homem está no conhecimento e na consciência" e que "nosso acesso ao mundo das escolhas éticas dispensaria a sensibilidade e a intuição" (HERMANN, 2010, p. 15). É diante desses dois movimentos - argumentação com poder do raciocínio e experiência estética - que a educação se torna espaço privilegiado de formação do ser humano. Contudo, não estamos diante de um dualismo ou de sobreposições, mas, sim, diante do humano em sua complexidade:

uma reação de reabilitação do sensível e do não conceitual, que trouxe, ao mesmo tempo, uma 'desdiferenciação' entre estética e aisthesis [...] na perspectiva de um novo conceito de razão, que incorpora o sensível. Estética e aisthesis podem ser reunidas justamente por não se tratar de uma teoria da arte, mas de uma racionalidade que incorpora também o conhecimento pela percepção sensível. (HERMANN, 2010, p. 125).

O questionamento próprio ou provindo de outrem pode se constituir em tarefa formativa, pois demanda a exposição do conjunto de valores que nos orientam, as convicções que possuímos, assim como o ato de ouvir com atenção a perspectiva que surge daquele com quem se estabelece o diálogo. Disso tem-se a oportunidade de algo que é igualmente importante, a possibilidade de reconstrução, em uma permanente autoformação.

\footnotetext{
${ }^{3}$ Por mais que Sen não adentre em questões estéticas, cabe uma referência ao tema, uma vez tendo sido apontada a necessidade de argumentação racional e capacidade perceptiva.
} 
Diálogo e autofomação, diálogo como autoformação, talvez esse seja o grande impulso da argumentação como método, não como uma síntese que surge nesse processo de exposição de si e crítica de si - mesmo que não, necessariamente, crítica por si -, mas como um constante questionar que conduz à revisão dos pressupostos próprios, dos fundamentos que nos sustentam e da projeção valorada de novas perspectivas de ação.

Sem querer imaginar a existência de pessoas totalmente altruístas, mas, também, sem imaginar uma situação de total egoísmo, estamos diante da exigência de um discernimento justo a ser construído pelo "acesso a informação relevante, a oportunidade de ouvir pontos de vista variados e exposição a discussões e debates públicos abertos. Em sua busca por objetividade política, a democracia tem que tomar a forma de uma racionalidade pública construtiva e eficaz" (SEN; KLIKSBERG, 2010, p. 54), para a qual também se exige capacidade teórica, pois esta permite "argumentar racionalmente sobre um assunto" (SEN, 2012, p. 34), gerando condição para ocorrer a argumentação e defesa saudável sobre algum objeto de debate.

Esse é o sentido posto ao termo arrazoabilidade, essa capacidade de considerar perspectivas provindas de diferentes locais e entrar em debate interativo guiado pela abertura da posição original e pela presença de consistência teórica que proporcione condições para o bom uso da razão. Os processos educativos ganham um espaço fundamental na formação de seres humanos capazes de realizar essa dimensão democrática e humana que deveria estar presente nas relações interpessoais.

Isso gera um desafio imenso em termos pedagógico-educacionais, no sentido de que a própria sala de aula tem a tarefa de se constituir em espaço de oportunidade para ouvir pontos de vista diversos, para os envolvidos se expressarem em debates, assim como, conseguirem avaliar e tomar decisões. Ou seja, a escola como espaço que prepare as crianças para não somente seguir algo, mas para escolher de modo arrazoado. Talvez seja esse o grande propósito da educação escolar, não somente

informar uma criança sobre culturas diferentes no mundo (inclusive a cultura à qual sua família possa, de um modo ou de outro, pertencer), mas também para ajudar a cultivar o uso da razão e o exercício da liberdade mais tarde na vida. Algo muito importante é perdido se as portas da escolha são firmemente fechadas no rosto de crianças pequenas, por conta de uma crença equivocada de que a tradição torna a escolha desnecessária. (SEN; KLIKSBERG, 2010, p. 47, grifo nosso).

Junto com a informação, o cultivo da razão e o exercício da liberdade, insiro a sensibilidade como sendo elementos a serem levados muito a sério quando o assunto é refletir sobre o sentido da sala de aula e o sentido da educação enquanto formação. Permitir que a cultura constituída historicamente esteja disponível, compreender a sequência histórica na qual nos inserimos, desenvolver as condições de reflexão crítica e construção crítica de sentido sobre a cultura na qual vivemos e sobre a cultura de outrem, considerar outrem não enquanto relação de poder, mas orientado pela dimensão estética (conforme posto acima), conseguir fazer escolhas e agir a partir de valorações, tudo isso compreendido não enquanto mera soma, mas enquanto fatores em inter-relações e inter-retroações, compõem o contexto educacional e ampliam o horizonte a partir do qual podemos pensar a formação do ser humano.

Referente à crítica a uma tradição que tende a tornar a escolha desnecessária, deve-se destacar que não se trata de uma negação do contexto e da tradição, mas permitir que a existência ou a continuidade de algo não seja consequência de imposição, passando por processos de escoIhas guiados pela reflexão, pela análise sobre os limites e alcances deste meio no qual o indivíduo nasce e é criado. Na busca pela arrazoabilidade ou, de modo mais intenso, ao pensar a educação como liberdade e para a liberdade, algo não pode ficar negligenciado: refiro-me ao fato de que o 
"direito humano que ficou perdido é, claro, o direito das crianças a uma educação ampla que as prepare para escolher, e não apenas para seguir” (SEN; KLIKSBERG, 2010, p. 48).

Em termos formativos, não é suficiente prepararmos as pessoas para, simplesmente, fazer determinadas coisas, mas gerar condições para que estas possam escolher de modo valorado e de modo arrazoado. Tem-se, então, uma articulação: juntamente com a condição de escolha e valoração, Sen põe a condição de agente, na indicação de não suficiência dos conhecimentos, valorações e escolhas por si mesmas, mas enquanto fatores que permitem a liberdade de realização. Em contexto da obra Desenvolvimento como liberdade ocorrem importantes considerações sobre a relação entre a condição de agente e a condição de escolha e valoração, relação essa posta sob os seguintes critérios: agente é (a) "alguém que age e ocasiona mudança e cujas realizações podem ser julgadas de acordo com seus próprios valores e objetivos"; (b) o "papel da condição de agente do indivíduo como membro do público e como participante de ações econômicas, sociais e políticas" (SEN, 2010, p. 34). Na primeira referência é indicada a relação entre as realizações e a formação de valores e estabelecimento de objetivos. Não é subjetivismo ou centralização em critérios próprios, uma vez que a valoração e os objetivos não são postos por Sem, sob o prisma da maximização do autointeresse, mas sob o "prisma da ética" (SEN, 2012, p. 31 e 35) e, nesse sentido é que se torna possível um "comportamento como comprometimento" enquanto membro do espaço público e suas respectivas dimensões econômicas, sociais, políticas.

É importante destacar, como síntese em decorrência das reflexões até aqui desenvolvidas, cinco movimentos que podem ser postos de modo interligado e que perpassam a concepção de pessoa: argumentação como poder do raciocínio, experiência estética, formação de valores e objetivos, capacidade de comprometimento e agência como membro do público. Esses quatro movimentos são fundamentais para a proposição da educação como capacidade e liberdade, tema da seção que segue.

\section{3 | EDUCAÇÃO COMO CAPACIDADE E LIBERDADE}

O conceito seniano de capacidade deriva da relação anteriormente destacada entre liberdade e realizações. Na distinção entre fazer algo e ser livre para fazê-lo reside uma qualificação que sai do mero procedimento em direção a valorações a partir dos quais realizamos algo. Nesse sentido podemos ser pessoas de capacidades. Nas obras Desenvolvimento como liberdade e $A$ ideia de justiça, ganha força a concepção de capacidade como "liberdade em realizar algo". Com o conceito de liberdade entramos no campo da ética, e a liberdade em realizar algo nos remete à pergunta socrática sobre como devemos viver, cuja resposta assumiu, com a economia de mercado, a característica de centralidade nas rendas e riquezas, desconsiderando o valor ético central da liberdade como condição para o bem-viver.

O que se perdeu em relação à concepção socrática é a possibilidade de, como participantes do diálogo, a partir da valoração do indivíduo de modo intrínseco, ampliar o entendimento e o conjunto de valores que mobilizamos no instante da ação. A valoração intrínseca remete a um sentido ético e antropológico cuja origem remete a Aristóteles, com a Ética a Nicômaco e a Política, onde a vida poiética, apesar de sua importância produtiva, não é o melhor critério de valoração, atribuindo à vida prática o papel valorativo baseado na constituição de um modo de vida orientado pelas virtudes morais.

No berço grego da civilização ocidental se encontra construído um ideal de vida que não está centrado na simples característica de instrumentalidade que alguém possa ter a partir de sua utilidade produtiva. Em seu livro Aristóteles e a educação, Cenci (2012, p. 62) destaca a: 
distinção entre o saber teórico e o saber prático e entre o saber prático e o poiético. A diferença originária entre o saber teórico e o saber prático está em que o primeiro é contemplativo e tem como fim conhecer como as coisas são, ao passo que o segundo visa o agir.

O elemento central a ser destacado é o poiético vinculado à produção ou aprimoramento de objetos "que é externo ao agente", enquanto que o saber prático, a práxis, "visa ao aprimoramento do sujeito que age, e a mudança por ele gerada é interna ao sujeito" (CENCl, 2012, p. 63). O sentido de instrumentalidade aqui defendido localiza-se nos termos da racionalidade presente na atividade poiética. A racionalidade presente nas ações práticas, por sua vez, assume outras características, os quais, na Ética a Nicômaco (1105a), são apresentados como condição para que o agente possa agir de modo justo e moderado: agir com conhecimento, que a ação passe pela deliberação e agir com atitude firme e imutável. Essa característica prática pressupõe um indivíduo capaz de valorar suas escolhas e decisões, e a avaliação deve considerar não simplesmente a ação desenvolvida, a realização, mas esse elemento intrínseco ao agente a partir do qual chegamos à ação e a desenvolvemos.

A abordagem das capacidades em Amartya Sen, com a base ética própria da relação entre liberdade e realização, ou liberdade de realização, dialoga com o sentido ainda aristotélico de que a qualidade do indivíduo deve ser considerada a partir da capacidade de realização, pelo fato de deliberar sobre sua ação e deliberar em função de seus atos, sem abstrair da necessidade de compromisso do indivíduo frente ao contexto no qual está inserido. Isso pode abrir espaço para preocupações deontológicas que, em linguagem seniana, é um termo genérico para as demandas do dever (SEN, 2011, p. 50). Seguindo o contexto teórico de agência e agente, anteriormente abordados, a ética de Sen não está fixa ao critério institucionalista e sua consequente dimensão deontológica, embora não descartando a necessidade institucional, até como espaço facilitador do exame de valores e do debate público. A via processual ou procedimental que se abre demanda atenção a critérios distintos, como a responsabilidade e o poder da agência, sendo difícil uma classificação segura de sua ética, pois abre margem à necessidade normativa e aos critérios de valoração e agência.

Voltando ao tema da deliberação própria, em primeiro lugar remete para a reflexão, motivação e valoração intrínseca sobre aquilo que devemos realizar. Em segundo lugar, é uma deliberação não reduzida ao interesse egoísta, dada a necessidade de "considerar a liberdade individual um compromisso social" (SEN, 2010, p. 10), ou seja, que possamos deliberar a partir de perspectiva ampla, na preocupação seniana, mas com base aristotélica, de que aquilo que nos motiva e aquilo que realizamos deve partir de avaliação inteiramente ética, adotando uma visão mais abrangente do bem (SEN, 2012, p. 20), o que pode significar o abandono ou a reconstrução da perspectiva totalmente individual.

Com esses pré-requisitos, direciono as reflexões para uma consequência da abordagem das capacidades. Dado o fato de que a capacidade é a liberdade de realizar algo com base em valorações arrazoadas, a pergunta pelo para quê da escola, da aula, dos conteúdos, das habilidades, ganha um enfoque diferenciado. A partir da abordagem das capacidades, tal pergunta é direcionada para aquilo que resulta, não em perspectiva utilitarista, mas enquanto valor intrínseco de como ela se relaciona com as escolhas, as valorações, a tomada de decisão e respectivas ações, a qualidade de vida de cada indivíduo envolvido.

Nesse sentido, o que se pode esperar de uma pessoa alfabetizada? Que diferencial ela constitui mediante sua condição de domínio de conteúdos estruturados nos currículos? Como isso repercute em sua liberdade de escolha, decisão e ação? A oportunidade de estudo é acompanhada pela escolha a tal bem? Que valoração ou que conjunto de valores estão presentes - se é que ocorre tal presença - quando uma pessoa frequenta a escola sem que sejam possíveis outras alternativas, ou quando escolhe frequentar consciente das outras alternativas possíveis ou, ainda quando não frequenta exatamente por ter outras alternativas? O que podemos efetivamente, reali- 
zar e como nossas escolhas e realizações repercutem em termos individuais e de sociedade?

Tais problemáticas apontam uma dificuldade na abordagem das capacidades: como os indivíduos podem se tornar aptos a valorar algo? Pode-se afirmar que a valoração perpassa pelos critérios básicos do aumento da liberdade e da responsabilidade. Não podemos pressupor que as pessoas consigam desde sempre ter liberdade de escolha e de agência, assim como conseguir colocar a responsabilidade como critério de ação, o que demanda atenção especial dos processos formativos, cujo compromisso deveria ser o de gerar as condições para a presença de tais critérios nos indivíduos.

Dedico algumas linhas a refletir sobre a responsabilidade. Em seu artigo intitulado The idea of justice, Sen referiu-se à muito adiada tentativa de concluir seu livro sobre a teoria da justiça e, nesse artigo, lançou aquilo que viria a se tornar uma das peças chaves do livro The idea of justice, a saber, "um chamado à ação da responsabilidade das pessoas" (SEN, 2008a, p. 335, tradução nossa), o que provocaria as mudanças necessárias para elevar o desenvolvimento humano e, posso dizer, provocaria a própria elevação moral, a qual pode ser posto como o ideal das teorias éticas e dos processos formativos.

A ação da responsabilidade gera uma intensificação em termos de filosofia prática, pois a responsabilidade passa a ser vista não somente como um critério que deve estar presente quando agimos, mas é aquilo que deve estar em realização a cada tomada de decisão e em cada procedimento que possamos levar à termo. Isso tem o sentido de uma assimetria de poder, que me leva a proceder de modo a favorecer outrem pois ele, por si mesmo, não o consegue. Junto a isso,

se alguma ação que pode ser livremente empreendida está ao alcance de uma pessoa (o que a torna factível), e se essa pessoa avalia que empreender a ação vai criar uma situação mais justa do mundo (o que a torna reforçadora da justiça), então esse é um argumento suficiente para que a pessoa considere seriamente o que deve fazer tendo em conta esse reconhecimento. (SEN, 2011, p. 240).

Essa ideia se vincula àquilo que Sen denomina "responsabilidade do poder efetivo", ou seja, "se alguém tem o poder de fazer a diferença na redução da injustiça no mundo, então há um forte e fundamentado argumento para que faça exatamente isso" (SEN, 2011, p. 305). Desse modo é que compreendo a expressão ação da responsabilidade, pois o critério não é o possível ganho pessoal, a reciprocidade ou simetria de forças entre os envolvidos, mas a responsabilidade do indivíduo frente uma situação que demanda intervenções. Assim, a responsabilidade se constitui no critério básico: ou permitimos que ela aja, ou não estamos no âmbito da valoração, repercutindo negativamente em termos de validade ética das realizações.

É importante retornar, a partir do exposto, ao problema da argumentação apresentado na seção anterior, pois junto com a responsabilidade está o problema da "oportunidade de raciocinar sobre o que ela [a pessoa] de fato quer", ou seja, se a pessoa teve a "oportunidade de avaliação arrazoada" (SEN, 2011, p. 335), o que repercute substantivamente em termos de liberdade. Estar em condições de raciocinar e, juntamente, abrir espaço para a ação da responsabilidade, rompe com o autointeresse e permite valorar qualquer realização em seus sentidos e desafios éticos no interior de uma comunidade.

Os debates sobre o tema comunidade merecem atenção devido a alguns motivos:

a) nossa identidade não se constrói somente intra-comunidade,

b) por mais que ocorra a pertença, disso não resulta uma necessária identificação com a comunidade,

c) a própria identificação, portanto, tem níveis diferentes de intensidade, dependendo do senso de pertença de cada indivíduo, 
d) as relações extracomunidade podem ser violentas, segmentárias, com postura absolutista, o que gera os choques de civilizações ou entre civilizações, exatamente por não admitir as influências, a identidade ou as diferenças constitutivas (e não competitivas) que possam existir para além das fronteiras comunitárias ${ }^{4}$.

Em ampliação, é fundamental que a própria comunidade consiga valorar suas realizações a fim de que não seja segmentária, abusiva no poder, perversa em suas ideologias e violenta no modo como se relaciona com outras culturas, outros povos.

É com base nessas ressalvas que devemos ler a expressão seniana, presente no conjunto de sua obra, de uma vida que temos razão para valorar. A oportunidade de raciocinar fazendo uso do recurso da teoria gera a qualificação interna a partir da qual a argumentação adquire um caráter racional, sendo que sua presença ou ausência ressoa na possível superação da arbitrariedade ou subjetivismo existente nas análises, escolhas e realizações.

Abre-se a necessidade de justificação das ações mediante a exposição de razões, pois não é um simples agir "de acordo com o que consideram como razoável, mas o que exatamente eles deveriam considerar como razoável e por quais razões específicas” (SEN, 2008a, p. 335, tradução nossa). Esse ato de se expor não busca somente a cooperação de outros, mas refere-se basicamente à validação/reformulação das razões de ação e das próprias ações resultantes. Embora a necessidade de permanente exposição das razões pareça um exagero procedimental, ao menos retira o risco de realizações subjetivistas e o risco de ser prejudicial com determinada ação. Essa é uma crítica importante, uma vez que a capacidade de estabelecer razões adequadas para as realizações não é algo imediato nos indivíduos. Do mesmo modo, não é imediata a capacidade de expor tais razões e, consequentemente, receber e admitir críticas ou aprovações. Para isso faz-se necessário o desenvolvimento da capacidade argumentativa envolvida "com a maneira correta de ver e tratar as outras pessoas, outras culturas, outras reivindicações [...]. Nós também podemos raciocinar sobre nossos próprios erros e tentar aprender a não repeti-los" (SEN, 2011, p. 77).

Esse é o "poder efetivo" defendido por Sen (2011, p. 336-337), do qual devemos estar em posse, mas que não retira a necessidade da "ajuda de outros" para produzir os resultados, para a efetividade. Tem-se a articulação entre aquilo que está sob meu controle e aquilo que exige a colaboração de outros, por isso a importância de arranjos sociais, de capacidades individuais e de esforços coletivos, pois posso não estar em condições de produzir determinado resultado, seja em termos de escolha, de decisão ou de ações. Nesse sentido é importante a consciência de coletividade, o senso comunitário, a instituição de arranjos sociais qualificados, não como condição de tutela ou de um pacto social como única condição de validade na ação, mas, sim, como espaços onde podemos tornar efetivas as ações da responsabilidade e responder ao convite à razão.

Importantes contribuições a essa abordagem provêm, por exemplo dos debates provocados por Frediani, Boni e Gasper (2014), os quais, na esteira da abordagem seniana, destacam o quanto determinados projetos podem influenciar na vida das pessoas, não enquanto mera produção de objetos ou bens, mas no sentido de contribuir para tornar valoradas as escolhas, as decisões, as realizações e a própria vida. A proposta é "compreender os participantes como 'agentes da mudança', ao invés de meros beneficiários” (FREDIANI; BONI; GASPER, 2014, p. 03, tradução nossa).

\footnotetext{
${ }^{4}$ Mesmo reconhecendo a grande relevância de tais reflexões, por questão de objetivos não dedicarei esforços, neste texto, para tais considerações. Ver, para maiores compreensões, de Amartya Sen, os livros: Identidade e violência: a ilusão do destino (SEN, 2015) e As pessoas em primeiro lugar: a ética do desenvolvimento e os problemas do mundo globalizado (SEN; KLIKSBERG, 2010), e, também, do mesmo autor, os artigos: Violence, identity and poverty (SEN, 2008b), e The fog of identity (SEN, 2009).
} 
Nesse sentido, apontamos duas direções de debate: a) a preocupação por quem decide ou age, ao mesmo tempo em que se pergunta pelo como e pelo que é decidido ou realizado; b) o foco está na qualidade de vida, no bem viver, e não na quantidade de bens, de produtos, que uma pessoa possui, no sentido de os indivíduos conseguirem converter tais bens em bem viver.

A preocupação é com o modo como os indivíduos vivem suas vidas e, se a posse de bens e direitos gera qualificação no modo como os indivíduos vivem suas vidas. A fim de ilustração, um indivíduo com acesso à escola (a alfabetização como um bem básico na sociedade) significa alguém apto a ler, compreender e interpretar, não somente um texto, mas o mundo e, assim, construir sentidos, formar-se (em perspectiva bem gadameriana), gerando uma qualidade de vida extremamente superior àquele que meramente é instrumentalizado pelos processos educativos? Um indivíduo que recebe assistência de saúde via Programa de Saúde da Família (PSF) está apto a qualificar os cuidados de si e do meio, enquanto resultado do desenvolvimento da consciência da importância de tal cuidado, ou permanece dependente da assistência fornecida por tal programa? A direção dada às respostas a essas e outras possíveis questões podem revelar se os arranjos sociais e os bens por eles gerados repercutem na elevação da qualidade de vida, no bem viver das pessoas e em sua condição de agentes.

Recolocando a ilustração acima, sabe-se da obrigatoriedade jurídica em frequentar a escola, mas não se sabe exatamente sobre a existência da escolha pela frequência, o que significa uma diferença extrema em termos de valoração. O problema está posto entre a oportunidade/escolha livre e ser forçado a algo, sendo isso o que diferencia entre um indivíduo tomar em consideração a "importância de seus próprios juízos e prioridades, com os quais a agência se relaciona" (SEN, 2011, p. 322) e, por outro lado, ser simples beneficiário passivo. Da liberdade relacionada com a agência surge, em Sen, o conceito de capacidade ou de indivíduo portador de capacidade.

A compreensão abrangente sobre o conceito de capacidade se preocupa em como a pessoa chegou a determinado resultado ou a determinada realização, se passou por processos de valoração ou significou somente uma ação resultante da instrumentalização, de prescrições institucionais ou provindas de ordenações de outras pessoas. Em termos abrangentes é considerada a oportunidade existente e o processo de escolha entre alternativas, como se disse acima, os quais repercutem na realização de algo e em seu resultado culminante. Na obra Desenvolvimento como liberdade ocorre um alerta sobre a distinção entre a escolha de algo quando não há alternativa e a escolha quando existem alternativas substanciais (SEN, 2010, p. 106).

Derivado disso, o desenvolvimento de habilidades e competências é concebido como permeado pela ampliação das capacidades. Estas exigem, como condição, os indivíduos efetivarem realizações de modo valorado, critério fundamental quando pensamos em seres realmente portadores de habilidades e competências. Ser capaz de realizar demanda a escolha, a valoração, a decisão. "O núcleo da abordagem das capacidades não é, portanto, apenas o que uma pessoa realmente acaba fazendo, mas também o que ela é de fato capaz de fazer" (SEN, 2011, p. 269), e por isso ocorre a distinção entre fazer algo e ser livre para fazê-lo (SEN, 2011, p. 271).

Portanto, ser capaz não significa simples seguimento ou simples treinamento, mas a efetivação de algo como resultado da ampliação informacional, do debate interativo, do uso da razão orientada por consistência teórica e argumentativa, da valoração sobre alternativas e fins. Efetivação, ou fazer algo, não se restringe ao domínio técnico-instrumental, mas é a capacidade de constituir qualidade subjetiva, uma elevação cultural própria de um ser humano íntegro em sua formação. Em evidência está o processo de formação humana como sendo processo de desenvolvimento de capacidades, portanto, como algo a ser proporcionado ao longo da vida e com o objetivo de ampliação da liberdade, coerente com o sentido de ser agente e se opondo à mera realização, conforme anteriormente desenvolvido. 
Mas e quando a escolha se torna um problema? Juntamente com a falta de arrazoabilidade acima destacada, a liberdade de escolha

\begin{abstract}
nos dá a oportunidade de decidir o que devemos fazer, mas com essa oportunidade vem a responsabilidade pelo que fazemos - na medida em que são ações escolhidas. Uma vez que uma capacidade é o poder de fazer algo, a responsabilidade que emana dessa capacidade - desse poder - é uma parte da perspectiva das capacidades, e isso pode abrir espaço para demandas do dever. (SEN, 2011, p. 49).
\end{abstract}

A pergunta pelo que devemos uns aos outros ${ }^{5}$ nos dá a indicação da responsabilidade que nos remete para o comprometimento social oriundo da abordagem das capacidades. É essa demanda ética que nos põe em um movimento "para além da busca de uma visão muito estreita do autointeresse, e podemos até descobrir que nossos próprios objetivos, quando bem avaliados, exigem que cruzemos completamente os limites estreitos da exclusiva busca autocentrada" (SEN, 2011, p. 63). Desse modo, a abordagem seniana sobre as capacidades não pode ser vista como um "individualismo metodológico" (SEN, 2011, p. 278), o que pressuporia um indivíduo em condições de abstrair completamente sua relação com o contexto no qual está inserido a ponto extremo de se colocar a salvo das interferências dos outros. A abordagem das capacidades não só

não supõe tal separação como seu interesse nas aptidões das pessoas para viver o tipo de vida que elas têm razão para valorizar traz influências sociais, tanto com relação ao que elas valorizam (por exemplo, 'tomar parte da vida da comunidade') quanto com relação às influências que atuam sobre seus valores (por exemplo, a relevância do exercício da razão pública na avaliação individual). (SEN, 2011, p. 279).

A escolha, o interesse e a própria realização se tornam problemáticas pela ausência do compromisso próprio da resposta à pergunta o que devemos uns aos outros. Com o compromisso, Sen propõe uma quebra com a ligação exclusivamente centrada no bem-estar individual a ponto de uma característica ser comum no todo de sua obra, a saber, se alguém se sentir em condições de agir em favor da solução de alguma situação injusta, é imperativo que o faça, independente de isso lhe causar algum tipo de sofrimento.

Com isso, estaríamos diante da possibilidade de ocorrer uma limitação do autointeresse no comportamento, originado pela comunidade que, uma vez permitindo espaços de exercício da razão pública, também permite que as prioridades, privilégios e benefícios encontrem a medida da justiça. Na ausência de comunidade, os privilégios, prioridades e benefícios seriam destinados totalmente a si mesmo ou a um segundo - com a comunidade, a presença de terceiros é inevitável e essa inclusão demanda justiça no estabelecimento de tais prerrogativas.

\footnotetext{
${ }^{5}$ Referência ao título do livro, What we owe to each other (SCANLON, 2000).
} 


\section{3 | CONSIDERAÇÕES FINAIS}

A educação como desenvolvimento de capacidade e liberdade nos leva a alguns caminhos complexos. Destaco a importância da superação da visão de repasse de conteúdos, muitas vezes amorfos e carentes de sentidos, em defesa da importância do conhecimento como riqueza constitutiva do indivíduo, o que permite ampliar o modo de compreender e interpretar o mundo. Ligado a isso está, de modo direto, o conceito de capacidade, pois todos os resultados com os quais chegamos ao final de um processo formativo encontra a preocupação com o modo pelo qual chegamos a esse resultado, com o que somos capazes de livremente realizar uma vez em posse dele, com a ressonância em termos de qualidade de vida e integridade humana surgida desse processo e de tais resultados. Terceiro, pressupõe uma concepção de sala de aula como espaço de potencialização da argumentação racional orientada pela abertura às diversas perspectivas e pelo rigor teórico.

A interdisciplinaridade também se constitui em um desses caminhos complexos que se abrem a partir da relação entre educação, capacidade e liberdade, uma vez que, com ela, nos abrimos aos riscos que envolve o diálogo entre perspectivas diferentes que se complementam na busca de respostas a um mesmo problema. Sobre a questão da interdisciplinaridade, cabe uma palavra a mais, apontando o desafio do diálogo interdisciplinar, a partir da qual é possível trilhar caminhos mais sóbrios quando o assunto é o ser humano e a sociedade em suas complexidades. Os profissionais das áreas aqui em questão - Educação, Filosofia e Economia -, uma vez abertos ao risco de um pensamento não reduzido à sua posição original, podem gerar a oportunidade de profundas experiências em produzir complexidades - em linguagem hermanniana -, tão fundamental ao avanço da pesquisa científica e das ações no mundo da vida e no mundo da vida escolar. Isso se intensifica pelo fato de as três áreas possuírem a origem ou o vínculo com a ética e o bem-viver, seja pela preocupação com a formação, seja pela necessidade de promoção de uma intensa experiência do pensar ou, ainda, pela preocupação com as motivações e realizações sociais. Mas essa cultura não se constituirá, ou não ganhará intensidade, se os próprios processos formativos desenvolvidos na educação básica e superior se mantiverem encerrados na tendência à fragmentação e na disputa em nome da pretensa hierarquia científica, o que, infelizmente, ainda é muito comum nos currículos que compõem os níveis de ensino.

Outro destaque deve ser posto na possibilidade de uma entrega séria a questionamentos, cuja consequência é a ampliação ou reconstrução de visões de mundo, de conjunto de valores, de características comportamentais. Para isso, a educação é algo muito maior do que processos de ensino e aprendizagem, se constituindo como processos formativos, onde o ensinar e o aprender assumem a premissa gadameriana de um autoformar-se e, a partir dos quais as pessoas possam compreender ou constituir os valores que permitem a liberdade de agir, orientado por juízos arrazoados e por prioridades arrazoadas. Conceber a educação como formação equivale a dar condições para que tenhamos consciência do poder efetivo da responsabilidade, ou seja, formar significaria permitir a ação da responsabilidade, enquanto um princípio ético-moral que retira do indivíduo a busca irrestrita pelo seu bem-estar e autointeresse, sendo capaz de perceber e admitir as relações interpessoais em suas interferências recíprocas. A abordagem das capacidades intensifica a concepção de educação para a responsabilidade e educação para a liberdade, portanto, educar passa a ser concebido como elevação cultural, moral e ética, a partir da qual seria possível o humano consciente de si, consciente no mundo no qual está inserido e daquilo que the compete quando o objetivo é a elevação da qualidade de vida ou bem-viver. 


\section{REFERENNCIAS}

ARISTÓTELES. Ética a Nicómaco. Edición bilingüe y traducción: María Araujo y Julián Marías. Madrid: Centro de Estudios Políticos y Constitucionales, 2009.

CENCI, A. V. Aristóteles e a educação. Belo Horizonte: Autêntica, 2012.

FLICKINGER, H.-G. À contramão das atuais correntes pedagógicas. In: LAGO, C.; FARINON, M. J. Articulações entre esclarecimento e educação. Campinas: Mercado das Letras, 2015. p. 133-158.

FREDIANI, A. A.; BONI, A.; GASPER, D. Approaching development projects from a human development and capability perspective. Jornal of Human Development and Capabilities, v. 15, n. 1, p. 1-12, Feb. 2014. Disponível em:<http://dx.doi.org/10.1080/19452829.2013.8 79014>. Acesso em: 04 mar. 2015.

HERMANN, N. Autocriação e horizonte comum: ensaios sobre educação ético-estética. Ijuí: Ed. Unijuí, 2010. (Coleção Fronteiras da educação).

SCANLON, T. M. What we owe to each other. Cambridge, MA: Harvard University Press, 2000.

SEN, A. A ideia de justiça. Tradução Denise Bottmann e Ricardo Doninelli Mendes. 1. reimp. São Paulo: Companhia das Letras, 2011.

Desenvolvimento como liberdade. Tradução de Laura Teixeira Motta. São Paulo: Companhia das Letras, 2010.
Identidade e violência: a ilusão do destino. Tradução José Antonio Arantes. São Paulo: Iluminuras: 2015.

The idea of justice. Journal of Human Development. v.9, n.3, p. 331-342, nov.2008.

. The fog of identity. Politics, Philosophy \& Economics, v. 8, n. 3, p. 285-288, 2009. Disponível em:

<h t t p: // journals. sagepub.com/doi/pdf/10.1177/1470594X09105388>. Acesso em:04 mar. 2015.

Sobre ética e economia. Tradução de Laura Teixeira Motta. 1. reimpr. São Paulo: Companhia das Letras, 2012.

. Violence, identity and poverty. Journal of Peace Research, v. 45, n. 1, p. 5-15, 2008b. Disponível em: < h t t p : / / journals. sa ge pub.com/doi/ pdf/10.1177/0022343307084920>. Acesso em: 04 mar. 2015.

SEN, A.; KLIKSBERG, B. As pessoas em primeiro lugar: a ética do desenvolvimento e os problemas do mundo globalizado. Tradução Bernardo Ajzemberg e Carlos Eduardo Lins da Silva. São Paulo: Companhia das Letras, 2010.

SHAKESPEARE, W. O Rei Lear. In: Obras escolhidas. Tradução de Millôr Fernandes e Beatriz Viégas-Faria. Porto Alegre: L\&PM, 2009. p. 697-768. 